\title{
ARTESANADO SEDERo Y CAPITAL COMERCIAL EN LA VALENCIA DEL SIGLO XVIII
}

por

\section{RICARDO FRANCH BENAVENT}

Universidad de Valencia

RESUMEN: El intenso desarrollo del "Verlagssystem» en la sedería valenciana dieciochesca puso de manifiesto las dificultades que tenia el artesanado tradicional para mantener su independencia económica. Con el fin de combatir esta debilidad, los artesanos adoptaron diversas iniciativas, que contemplaron desde la constitución de una compañia por acciones hasta la creación de un pósito para favorecer el abastecimiento de materias primas por parte de las fábricas. El proyecto más importante fue la constitución de la Compañía de Nuestra Señora de los Desamparados en 1772. Pero la exi. gencia de la Junta General de Comercio de que permitiese la participación en su accionariado de todas clases sociales, al no ir acompañada por la modificación de la claúsula que establecta la reserva de los cargos directivos para el artesanado sedero, provocó el desencadenamiento de graves conflctos que determinaron su fracaso final.

Palabras Clave. España, Valencia, H.* Moderna. Seda, artesano, industria, Verlagssystem, siglo xvir.

ABSTRACT: The intense development of the "Verlagssystem» in the XVHI century silk industry in Valencia showed the difficulties of the traditional craftsmen to keep their economic independence. In order to fighy against it, the craftsmen adopted several initiatives, which dealt with the constitution of a share-holding company, as much as with the creation of a communal store to favour the suppley of raw materials to the factories. The most important project was the constitution of the "Compañia de Nuestra Señora de los Desamparados" in 1772. But the requirement of the General Board of Commerce to allow all the social classes to take part in shareholders, as it was not accompanied by the modification of the clause that established the reservation of the managines charges for the silk craftsmen, provoked the unchaining of serious conflicts which brought its final failure.

Hispanì, LVI1/1, núm. 195 (1997) 93-114 
KEY WORDS: Spain, Silk, Craftsman, industry, Valencia, Verlagssystem, eigthteenth century.

\section{I) INTRODUCCION: EL DESARROLLO DEL "VERLAGSSYSTEM" EN LA SEDERIA VALENCIANA DHECIOCHESCA}

El crecimiento experimentado por la sedería valenciana durante el siglo XVII determinó la consolidación de un nutrido sector artesanal. Si a principios de la centuria los maestros integrados en el colegio del arte mayor de la seda rondaban la cifra de 500 , en la década de 1750 ya superaban el millar, y en 1801 llegaron a ascender a 1.889 '. Por su parte, la corporación gremial que regía su actividad experimentó un paralelo fortalecimiento, tratando de elevar su distinción social con la sustitución de su anterior denominación de gremio por la de colegio en 1686 y, sobre todo, logrando extender efectivamente su jurisdicción al conjunto del País Valenciano a partir de la aprobación de las ordenanzas de $1736^{2}$. Sin embargo, la regulación gremial de la manufactura no consiguió preservar la cohesión social y la independencia económica del artesanado, y, progresivamente, se fue afianzando la diferenciación interna de sus miembros y extendiéndose el control de la actividad por parte del capital comercial.

El reflejo más evidente de este proceso de transformación de la estructura artesanal es el desarrollo del «Verlagssystem». Hasta el momento sólo se han podido proporcionar al respecto estimaciones globales que sitúan los telares controlados por los comerciantes-fabricantes (incluida la Fábrica de los Cinco Gremios Mayores) en torno a la tercera parte de los activos al comienzo de la década de $1760^{3}$. Sin embargo, otras fuentes localizadas recientemente nos impulsan a sostener que el proceso se hallaba mucho más avanzado. En el marco de la polémica mantenida entre los fabricantes y los cosecheros en la segunda mitad de la década de 1730 con respecto a la política de exportación de la materia prima, los segundos promovieron un registro judicial de los telares existentes en la ciudad de Valencia, que fue efectuado entre el 28 de abril y el 10 de mayo de 1738 . Se trataba de unas fechas muy alejadas de la cosecha, por lo que sólo se hallaron corrientes 1.419 telares de los 3.419 que sostenía que existían el colegio del arte mayor de la seda. En todo caso, en el propio registro se indicaba que los maestros que tenían telares corrientes eran 582 de los 934 que se hallaban «en exercicio", descontando los 57 «maestros pobres». Por tanto, sólo el $62.31 \%$ de los maestros que podían hacerlo se mantenían en actividad. Resulta imposible saber si los maestros que tenían sus telares parados trabajaban o no por su cuenta, pero no cabe duda que su

1 DIEZ, F. Viles y mecánicos. Trabajo y sociedad en la Valencia preindustrial. Valencia, 1990. Pág. 70.

2 Martinez Santos, V. Cara y cruz de la sedería valenciana (siglos xVII-xIX). Valencia, 1981. Pág. 32 y 67.

3 Martinez Santos, V. libid. Pág. 120.

Hispania, LVIJ/, núm. 195 (1997) 93-114 
situación económica debía de ser muy precaria y que su posible independencia se hallaría muy amenazada. En todo caso, lo cierto es que la inmensa mayoría de los que se mantenían en activo trabajaban por encargo (ver cuadro n. ${ }^{\circ}$ 1). Por sí solos, los telares que lo hacían por «cuenta de mercaderes» ascendían a 742, es decir, el $52.30 \%$ de los que se hallaron corrientes. Pero al papel empresarial que ejercía el capital mercantil se añadía el efectuado por los propios artesanos que habían logrado enriquecerse. Así, en el registro se indicaba que eran 247 los telares «...que los terciopeleros hazen travaxar a diferentes maestros por su quenta...». Por tanto, los telares que eran manejados por artesanos que habían logrado mantener su independencia eran solo $430^{4}$. Tal vez la representatividad de estos datos se encuentre afectada por la fecha en que se realizó el registro y el elevado índice de paro que consiguientemente se constató. Pero el hecho de que el $69.7 \%$ de los telares activos se hallasen sometidos al "Verlagssystem» revela claramente el elevado grado de descomposición interna que había sufrido, ya en unas fechas tan tempranas, la vieja estructura artesanal y la enorme debilidad económica de sus miembros, la inmensa mayoría de los cuales o bien habían perdido su independencia o bien se veían afectados por el paro estacional.

Desgraciadamente, la otra muestra que se ha logrado localizar sobre el desarrollo del "Verlagssystem» se sitúa en un momento crítico. Su origen es el registro de los empresarios y artesanos sederos que en 1771 obtuvieron permiso para comprar seda. La medida se adoptó ante la mala cosecha que se obtuvo en dicho año, que, según las cifras de los manifiestos, sólo ascendió al $42.42 \%$ de la del ejercicio anterior, lo cual provocó una intensa paralización de las fábricas. De ahí que en el registro de telares que efectuó el colegio del arte mayor de la seda en febrero de 1772 hallase 2.436 parados, manteniéndose únicamente en actividad 1.162. La documentación localizada sólo comprende a 509 telares, es decir, el $43.8 \%$ de los que se hallaron activos en el registro del colegio, por lo que sus resultados deben ser adoptados con mucha cautela. Sin embargo, la imagen que se desprende de su análisis se sitúa perfectamente en la línea apuntada por el registro de 1738 (ver cuadro $n .^{\circ} 1$ ). Los comerciantes en sentido estricto controlaban el $49.31 \%$ de los telares. Y a ellos se podían añadir otros empresarios no vinculados al arte mayor de la seda, que daban trabajo al $2.35 \%$ de los telares. De nuevo, pues, los artesanos sederos sólo lograban mantener la dirección de algo menos de la mitad de la fábrica. Pero el sector de ellos que había asumido funciones empresariales y controlaba la actividad de otros compañeros englobaba ahora el $29.27 \%$ de los telares, con lo que los maestros que mante-

4 Los datos derivados del registro de telares de 1738 se hallan en A.M.V. (Archivo Municipal de Valencia). Gremios en general. Caja 7. Exp. n. ${ }^{0} 11$. Desgraciadamente, solo se ha conservado un resumen de los resultados totales, pero el distinto carácter de los telares manejados por los artesanos aparece perfectamente reflejado. Si bien todos los artesanos debían de conservar la propiedad de los telares, la gran mayoría trabajaba «...por cuenta de...» comerciantes o de otros artesanos que ejercian funciones empresariales. Es evidente que ello suponia el control de las materias primas y del producto finalmente elaborado, por lo que perfectamente se puede denominar corno "Verlagssystem» al sistema de producción resultante. 
nían su independencia económica en las condiciones tradicionales sólo poseían el $19.05 \%$ de los instrumentos de producción ${ }^{5}$.

\section{CUADRO I}

DISTRIBUCIÓN POR SECTORES DE LOS TELARES ACTIVOS EXISTENTES EN 1738 $X$ DE LOS REGISTRADOS EN 1771

$\begin{array}{lcccc} & & 1738 & \underline{1771} & \\ & \text { Telares } & \% & \text { Telares } & \% \\ \text { Comerciantes } & 742 & 52.30 & 263 & 51.70 \\ \text { Artesanos-empres. } & 247 & 17.40 & 149 & 29.20 \\ \text { Artesanos } & 430 & 30.30 & 97 & 19.10 \\ \text { TOTAL } & 1419 & & 509 & \end{array}$

Fuentes: A.M.V. Gremios en general. Caja 7. Exp. n." 11. A.C.A.M.S.V. Sig. 3.5.2. Leg. 7.

En conjunto, a pesar de que los datos obtenidos corresponden a momentos en que existía una elevada tasa de paro, su coincidencia en reflejar un intenso desarrollo del "Verlagssystem" no puede proceder simplemente de la incidencia de circunstancias excepcionales. Las cifras son demasiado rotundas, ya que si en 1738 el nuevo sistema de organización de la producción comprendía al $69.7 \%$ de los telares activos, en 1771 se extendía ya al $80.95 \%$ de la muestra localizada. Estos porcentajes solamente pueden flexionar a la baja considerando que la mayor parte de los telares parados pertenecerían a maestros independientes. Pero esta suposición, además de que no es segura, lo que nos pondría de manifiesto es la enorme fragilidad de estos modestos artesanos, cuya actividad se vería dramáticamente afectada por las circunstancias adversas. Y este serfa el mecanismo que, en último extremo, les conduciría a la pérdida de su independencia económica. Podemos admitir, pues, que las proporciones se hallen ligeramente magnificadas, pero lo que no cabe duda es que el proceso de desintegración de la vieja estructura artesanal se hallaba ya muy avanzado.

Realmente, los factores que dificultaban el mantenimiento del modelo tradicional de organización de la producción eran muy diversos. Como toda actividad textil de Antiguo Régimen, la sedería también requería la coordinación de las diversas fases del proceso de producción, lo que favoreció la actividad empresarial de los comerciantes y de los artesanos enriquecidos. En la misma línea impulsó la lejanía de los mercados de destino. Pero, aparte de estas cir-

${ }^{5}$ A.C.A.M.S.V. (Archivo del Colegio del Arte Mayor de la Seda de Valencia). Sig. 3.5.2. Leg. 7. En este caso, la relación de dependencia de la gran mayoría de los artesanos con respecto a los comerciantes o a otros compañeros que ejercían funciones empresariales aparece reflejada con mayor evidencia, ya que la documentación se refiere a las personas que obtuvieron permiso para comprar la materia prima. De ahi que cada artesano o empresario tuviese que especificar el número de telares de que disponía o la relación de artesanos (con sus respectivos telares) a los que encargaba el trabajo.

Hispania. LV]I/l, núm. 195 (1997) 93-114 
cunstancias comunes, en la sedería existían algunos factores específicos que amenazaban la independencia económica de los artesanos modestos. Básicamente procedían del elevado precio que alcanzaba la materia prima y del origen agrícola de ésta, lo que determinaba la existencia de bruscas oscilaciones de las cosechas y de un marcado ciclo estacional en su comercialización. En principio, hay que tener en cuenta que la seda era una materia prima muy cara. Durante la segunda mitad del siglo xviI su cotización osciló entre los 60 y 80 sueldos por libra de 12 onzas, mientras que, por ejemplo, el salario habitual de un oficial de la construcción se situaba en torno a los 8 sueldos diarios. Si aceptamos la estimación de los cosecheros de que un telar consumía una media de 120 libras anuales de seda, cifra que los artesanos elevaban a 200 , la inversión mínima que debía de realizar un artesano anualmente rondaría los 8.000 sueldos, lo que suponía un esfuerzo considerable para una economía modesta ${ }^{6}$. Ciertamente, el artesano no se vería obligado a desembolsar íntegramente este capital si procedía a enajenar rápidamente las manufacturas que realizaba. Pero ello le condenaba a comercializarlas únicamente en el mercado local, puesto que si las remitía a otras plazas debía de aceptar las inevitables esperas en la recuperación del capital invertido. De ahí que los comerciantes se situasen en una clara posición de dominación con respecto a los modestos artesanos. Pero si éstos lograban enajenar rápidamente sus manufacturas tropezaban aún con otra dificultad añadida: el movimiento estacional que experimentaban tanto los precios como la propia comerciali* zación de la seda. Los precios más bajos se conseguían entre junio y agosto, que era cuando se comercializaba la mayor parte de la nueva cosecha y los grandes empresarios efectuaban sus mayores adquisiciones. Posteriormente, los precios tendían al alza, sobre todo a partir de enero, cuando la materia prima escaseaba en el mercado y se espaciaban las operaciones de comercialización ? . Este ciclo se acentuaba en los años en que se producía una mala cosecha. Y esta circunstancia no era nada infrecuente en una producción tan sensible a las variaciones meteorológicas, ya que los fríos de primavera podían destrozar la producción de hoja, y la humedad dificultar el desarrollo de los gusanos. De ahí que, además de las cosechas catastróficas, como las de 1771 y 1784 en la segunda mitad del XviI, fuesen bastante frecuentes las cosechas mediocres. Todo ello determinaba que en las épocas más alejadas de la cosecha se experimentase una notoria escasez de materia prima que provocaba una parcial paralización de las fábricas. Aparte de diversos testimonios que apuntan en esta dirección, los propios registros de telares efectuados por

${ }^{6}$ Los precios de la seda en PALOP, J.M. Fluctuaciones de precios y abastecimiento en la Valencia del siglo XVII. Valencia, 1977. Págs. 261 y ss. Al mismo autor se deben las referencias sobre los niveles salariales. Conviene aclarar que el sueldo constituía la vigésima parte de una libra valenciana, y que ésta equivalía a 15 reales y 2 maravedis de vellón. Las estimaciones sobre el consumo de seda de un telar en MARTINEZ SANTOS, V. Op. cit. Págs. 54-56.

7 Sobre la estacionalidad en la comercialización de la seda ver FRANCH, R. «La comercjalización de la seda valenciana a finales del Antiguo Régimen: Ei «contraste» de la ciudad de Valencia». Revista de Historia Económica. Año VIH. N.² 2. Págs. 271-304.

Hisponia, LV11/1, núm. 195 (1997) 93-114 
el colegio del arte mayor de la seda pueden ilustrar esta situación. Ya que, en contra de lo que parece deducirse de la obra de V. Martínez Santos, los datos proceden de las visitas realizadas en un momento determinado del año, que raras veces suele ser el mismo en los diversos ejercicios. Al carecer, por tanto, de homogeneidad, difícilmente pueden revelar el grado de desarrollo de la sedería. En cambio, si se les ordena mensualmente, pueden servir para constatar la existencia de una cierta estacionalidad en la actividad manufacturera, puesto que las cifras más elevadas de telares parados se solían alcanzar en los registros efectuados en los meses más alejados de la cosecha sedera ${ }^{8}$. En todo caso, lo que resulta evidente es que el modesto artesano experimentaba unas graves dificultades para lograr un correcto abastecimiento de materias primas, lo que, al combinarse con los factores anteriormente analizados, amenazaba gravemente su independencia económica.

Evidentemente, el artesanado sedero era perfectamente consciente de sus debilidades, y de ahí que emprendieșe diversas iniciativas encaminadas a aunar esfuerzos con el fin de preservar su posición tradicional. Las tentativas fueron bastante frecuentes y contemplaron la adopción de fórmulas muy diversas: desde la creación de un pósito destinado a favorecer el abastecimiento de materias primas, hasta la constitución de una gran compañía que ejerciese funciones empresariales y reuniese a la mayoría de los maestros. Estos proyectos no deben ser contemplados como meras medidas defensivas encaminadas a mantener la tradicional estructura corporativa. Su éxito podría haber permitido al colegio del arte mayor de la seda jugar un papel positivo en el proceso de industrialización. La experiencia desarrollada en el caso de Alcoi demuestra que esta vía era perfectamente posible. Sin embargo, el fracaso final de todos los proyectos emprendidos por el artesanado sedero valenciano, y la responsabilidad del colegio en la quiebra definitiva del más importante de todos ellos, puede también poner de manifiesto la posible excepcionalidad del caso de Alcoi, ya que, como ocurrió en la mayoría de los casos, también en la ciudad de Valencia las corporaciones gremiales obstaculizaron el surgimiento del capitalismo industrial ${ }^{9}$.

8 Estas conclusiones se derivan del análisis de una copia de las visitas efectuadas por el colegio entre 1760 y 1780 . A.M.V. Documentación Lonja. Caja 45. En concreto, Jas fechas de las visitas y el número de telares parados que encontraron fueron los siguientes: julio 1760: 1.800 (hay que tener en cuenta que, aunque en julio ya se había obtenido la cosecha, la materia prima estaba recibiendo las primeras operaciones de semielaboración previas al tejido); enero 1763: 1.298; junio 1764: 2.032; octubre 1766: 1.263 (la cosecha de 1766 fue mediocre y, al otorgarse permisos de exportación de 150.000 libras de seda, existió una grave escasez que determinó que ya no se volviesen a conceder licencias de exportación en las cosechas siguientes); mayo 1767: 1.915; noviembre 1768: 703; octubre 1769: 889; febrero 1772: 2.436 (cosecha catastrófica de 1771); septiembre 1777: 527; septiembre 1778: 352; abril 1780: 910 .

9 Sobre Alcoi ver ARAClL, R. y García BonafE, M. Industrialització al País Valencià. El cas d Alcoi. Valencia, 1974. Una reciente sintesis en la que se insiste en el papel obstaculizador de los gremios en el distrito que lideró la industrialización del subsector textil lanero en España es la de Benaul, J. M. «Los orígenes de la empresa textil lanera en Sabadell y Terrassa en el siglo xvlis Revista de Historia Itdustrial. N.0 1. Barcelona, 1992. Págs. 39-61. La cerrada defensa de

Hispania, LVIL/, núm. 195 (1997) 93-114 


\section{LOS ESFUERZOS PARA LA CONSTITUCION DE GRANDES COM- PAÑIAS POR ACCIONES A MEDLADOS DEL SIGLO XVIII}

Los primeros proyectos emprendidos por el artesanado sedero que se han logrado localizar pueden insertarse en el marco de la política de fomento de la actividad industrial que se llevó a cabo en la década de 1740 y que se materializó en la creación de diversas compañías privilegiadas de «comercio y fábricas» 10 . Sin embargo, en el caso valenciano el impulso gubernamental parece menos decisivo. Resulta significativo, en este sentido, que la primera iniciativa se efectuase en 1745, es decir, antes de que José de Carvajal y Lancaster, el principal promotor y protector de este tipo de compañías, accediese a la presidencia de la Junta General de Comercio y Moneda. Igualmente, en ninguno de los dos proyectos localizados se aprecia la intervención de las autoridades locales, que solieron jugar un papel importante en la promoción inicial de aquellas sociedades. Todo ello les puede otorgar un cierto grado de originalidad, en el sentido de que no constituían una simple respuesta a la política diseñada por la monarquía. Su impulso fundamental procedía del propio artesanado, ansioso por mejorar la situación de la fábrica y poder disponer así de mayores oportunidades de trabajo, evitando su creciente dependencia del capital mercantil o manufacturero. El mecanismo adoptado para lograr este objetivo sí que se ajustaba perfectamente a la política gubernamental de signo mercantilista dominante en la época: se trataba de crear una compañía por acciones que lograse la protección real y gozase de privilegios y exenciones fiscales. Sin embargo, fue tal vez la espontaneidad de las iniciativas y la consiguiente falta de apoyo oficial lo que determinó su fracaso final.

La primera tentativa se realizo en 1745 , y sus principales promotores fueron doce maestros del colegio del arte mayor de la seda, quienes el día 8 de abril aprobaron notarialmente los capítulos que debian de regir la nueva compañía ". Esta adoptaba la razón social de "Compañía Valenciana" y se ponía bajo la protección de la Virgen de los Desamparados, declarando expresa.

sus prerrogativas que realizó el colegio del arte mayor de la seda de Valencia y su campaña en contra de los decretos de liberalización de la producción que emitió la monarquia a finales del siglo XVıI en FRANCH, R. «La sedería valenciana en el siglo xvilı. España y Portugal en las rutas de la seda. Diez siglos de producción y comercio entre Oriente y Occidente. Barcelona, 1996 Págs. 201-222.

10 Sobre las compañías de comercio y fábricas relacionadas con la actividad sedera, pueden verse los trabajos de Rodriguez GonzAlez, M. C. «La Real compañía de comercio y fábricas de Extremaduran. Cuadernos de investigación histórica. N. 6. Madrid, 1982. Págs. 39-72. Rico LINAGE, R. «La Real compañfa de fábricas y comercio de Granada: su cédula de creación». Actas del I congreso de historia de Andalucía. Andalucía moderna (siglo xvII). Vol II. Córdoba, 1978. Págs. 159-175. Sanz Sampelayo, J. Granada en el siglo xvil. Granada, 1980. Pág. 77-92 y Garcla Ruiperez, M. La Real compañía de comercio y fábricas de Toledo. Toledo, 1986.

11 A.C.C.Ch.V. (Archivo del Colegio del Corpus Christi de Valencia), Protocolos. Sig. 3.931. Año 1745. Fols. 83r-88r. 
mente que su objetivo era conseguir "...el restablecimiento y crédito de las fábricas de seda de esta ciudad...». Sin embargo, aunque la iniciativa surgía de los medios artesanales, la compañía se abría al resto de la sociedad, aceptando la participación de a...todas las personas de qualquier estado, secxo y calidad...». Para ello bastaba con adquirir las acciones que se emitirían, cuyo valor unitario se establecía en 200 libras en los primeros cuatro años de funcionamiento, aunque se elevaba a $\mathbf{3 0 0}$ libras en los cuatro años siguientes y a 400 libras en el tercer cuatrienio, tras cuya finalización se cerraba la emisión de acciones, pudiéndose sólo participar en la sociedad a través de su adquisición en el mercado. Pero, a pesar de su carácter abierto, la compañía se orientaba prioritariamente a integrar en su seno a los miembros del colegio del arte mayor de la seda. Y de ahí que, teniendo en cuenta su escaso poder económico, se estableciese la existencia de acciones de un valor inferior destinadas exclusivamente a ellos. En el primer cuatrienio su precio sería de 50 libras; en el segundo de 100; y en el tercero de 200. Esta diversidad de valores de las acciones determinó la necesidad de precisar que los beneficios se distribuirían en función del capital invertido, y no de las acciones poseídas. Además de la discriminación establecida a la hora de suscribir las acciones, los artesanos también disponían de ciertas prerrogativas en el gobierno de la sociedad. Este se hallaba encomendado a 5 directores, de los que uno, al menos, debía ser maestro del arte mayor de la seda. Y la misma condición debían de tener obligatoriamente los tres subdirectores que se encargarían de la compra de las materias primas y de la dirección de la fábrica. Los cargos de tesorero y de secretario completaban la junta directiva. Todos ellos debían de ser elegidos por la Junta General de Accionistas, en la cual el capital requerido para disponer de un voto era de 2.000 libras. Finalmente, asumiendo la práctica habitual de este tipo de sociedades, se facultaba a los directores para que se dirigiesen al rey solicitando $\alpha . . . s u$ Real Protección con algunas gracias, franquezas de derechos, exenciones de los que en ella entienden, y, especialmente, el nombramiento de un juez conservador para la defensa y conocimiento de los intereses de la compañía y sus dependientes...». Es decir, la pretensión de convertirse en una compañía privilegiada parece evidente. Sin embargo, a pesar de que el proyecto parecía muy bien meditado y de que aún mes y medio después de su aprobación se nombraba como tesorero a la compañía de Pedro y Pedro Verges ${ }^{12}$, no se ha logrado localizar ningún rastro posterior sobre su actividad.

La otra iniciativa adoptada por el artesanado sedero fue la constitución de la Compañía de San Antonio de Padua el 7 de febrero de 1751, cuyos capítulos se conservan impresos ${ }^{13}$. Sus pretensiones parecían más modestas, puesto que el valor de cada acción se fijaba en 40 libras. Igualmente, los argumentos que se adoptaban para justificar el papel de la sociedad parecían dirigidos especialmente a las categorías sociales inferiores. Así, se insistía en la necesi-

12 A.C.C.Ch.V. Sig. 3.931. Año 1745. Fols. 115v-116v,

13 B.U.V. (Biblioteca Universitaria de Valencia). Sig. F-301. Folleto n. ${ }^{\circ} 8$.

Hispania, LVII/1, núm. 195 (1997) 93-114 
ARTESANADO SEDERO Y CAPITAL COMERCIAL EN LA VALENCIA DEL SIGLO XVI11 10 !

dad de remediar la pobreza del artesanado sedero, denunciándose que "....aprovechándose de ella muchos poderosos y hacendados sacan y consiguen de este mismo abandono excesivas ganancias...». La compañía trataría de combatir esta situación promoviendo «...los surtimientos y fábricas de sedas de esta ciudad y arte mayor de ella...». A pesar de todo ello, la compañía se declaraba abierta a la participación de todos los sectores sociales. Pero, como en el caso anterior, se orientaba prioritariamente al artesanado sedero. Y de ahí que se tratase de facilitar su integración admitiendo que pudiesen proceder a la entrega del capital de una acción en cuatro plazos anuales de 10 libras. Igualmente, los maestros del arte mayor de la seda gozaban de una cierta preferencia en la dirección de la compañía, cuya estructura era bastante compleja. En principio, los accionistas se diferenciaban entre los simples «interesados» y los "vocales». Estos últimos, que debían oscilar entre 60 y 100 y se renovarían cada 8 años, serían los únicos que intervendrían en el gobierno de la sociedad y tendrían opción a formar parte de sus cargos directivos. Pues bien, la mitad de ellos debían de ser necesariamente maestros del arte mayor de la seda. Pero, además, en la Junta de Dirección, que estaba integrada por un director general, dos subdirectores, 6 diputados, un tesorero, un contador, un interventor y un secretario, aquellos también se aseguraban una práctica mayoría al exigir que los diputados se escogiesen necesariamente de entre sus miembros. Por tanto, el control artesanal de la sociedad estaba prácticamente garantizado. Finalmente, como en el caso anterior, también se preveía la solicitud de protección real y de franquicias y privilegios que favoreciesen el desarrollo de la compañía. Sin embargo, ésta tampoco gozó de una excesiva vigencia. A través de algunas escrituras de poder otorgadas por diversos accionistas en agosto de $1753^{14}$, conocemos la existencia de autos judiciales para proceder a la recuperación de los capitales invertidos, lo que nos indica que, si bien se superó la fase del mero proyecto, su fracaso fue bastante rápido.

\section{LAS INICIATTVAS TENDENTES A FACILITAR EL ABASTECIMIENTO DE MATERIAS PRIMAS POR PARTE DE LAS FABRICAS}

El fracaso de las iniciativas del artesanado para la constitución de grandes compañías y la persistencia de los factores que minaban la independencia de los maestros pudieron impulsar la intervención de la propia corporación gremial. Ahora bien, ésta se limitó a tratar de combatir el problema que más contribuía al empobrecimiento de sus miembros, intentando únicamente garantizar un abastecimiento regular de materias primas para las fábricas, sin pretender inmiscuirse en las propias actividades empresariales o de comercialización del producto elaborado. Es evidente que la diferenciación social que ya existía entre los integrantes del colegio debió de influir en la moderación de

14 A.C.C.Ch.V. Protocolos. Sig. 7.014. Año 1753. Fols. 85r-93v.

Hisponia. LVIJ/I, núm. 195 (1997) 93-114 
los objetivos, limitando éstos al ámbito que más podía interesar a la inmensa mayoría de ellos y que menos se interfería en sus posibles negocios particulares. No en vano, la década de 1750 fue crucial en el surgimiento de una burguesía sedera de origen artesanal que fue la que apadrinó la creación de los Cuerpos de Comercio en $1762{ }^{15}$. Y resulta significativo que esta institución promoviese en 1765 la creación de una nueva compañía por acciones, pero destinada únicamente al abastecimiento de materias primas para las fábricas.

La primera iniciativa adoptada para la constitución del pósito parece que se remonta al acuerdo tomado por la junta del colegio del arte mayor de la seda el 27 de noviembre de 1751. El hecho de que se efectuase en el mismo año en el que se aprobaron los capítulos de la Compañía de San Antonio de Padua puede poner de manifiesto bien la escasa efectividad que alcanzó este proyecto o bien la poca confianza que el colegio tenía en su desarrollo. Lo cierto es que frente a la escasa trascendencia que habían tenido los proyectos anteriores, la propuesta adoptada ahora por la propia corporación fue aceptada inmediatamente por la Junta General de Comercio en sus órdenes de 17 de diciembre de 1751 y de 5 de febrero de 1752. El objetivo del colegio se limitaba simplemente a tratar de facilitar la adquisición de materias primas por parte de sus miembros. Según sus palabras, se trataba de «...poder evitar los caros y subidos precios con que se venden las sedas torcidas y poder socorrer el alivio de los fabricantes del colegio...». Y la actividad del pósito consistiría simplemente en disponer de un «...repuesto de sedas correspondiente, comprándolas en rama, haciéndolas torcer, y después venderlas al dinero a los fabricantes maestros por aquel precio o precios que parecieren proporcionados...». El volumen de materia prima que se pensaba manejar tampoco era excesivo, ascendiendo a unas 8.000610 .000 libras de seda anuales ${ }^{16}$. Es decir, se trataba de atenuar uno de los problemas fundamentales que podían obstaculizar el funcionamiento de las fábricas, pero sin interferir con la iniciativa privada en las actividades de elaboración y comercialización del producto. Estos eran los límites que marcaba claramente la burguesía sedera, como veremos posteriormente. A pesar de su modestia, el proyecto contó con la oposición del colegio de torcedores de seda, cuyas protestas fueron desestimadas por la Junta General de Comercio. Sin embargo, el problema más grave fue la inexistencia de capitales con los que emprender la actividad del pósito. Como única solución, el colegio pidió permiso para endeudarse por una cantidad máxima de 30.000 libras valencianas, solicitud que fue aprobada por la Junta General de Comercio por orden de 28 de septiembre de 1753. Pero hasta cuatro años después no se consiguió encontrar un prestamista, y, aún así, el capital que entregó era claramente inferior al límite permitido. En efecto, el 31 de julio de 1757 el colegio otorgaba una escritura de obligación en favor de Don Fernando de Llano y Lezama, caballero de la

\footnotetext{
15 Franch, R. Crecimiento comercial y enriquecimiento burgués en la Valencia del siglo XVII. Valencia, 1986. Págs. 162-165.

If Todos estos datos están recogidos en la escritura de obligación que el colegio otorgó con el fin de obtener un préstamo con el que iniciar el funcionamiento del pósito. A.C.C.Ch.V. Protocolos. Sig. 28.163. Año 1757. Fols. 222r-234r.

Hispania, LVl]/1, núm. 195 (1997) 93-114
} 
ARTESANADO SEDERO Y CAPITAL COMERCIAL EN LA VALENCIA DEL SIGLO XVII 103

orden de Santiago residente en Madrid, reconociendo haber recibido 20.000 libras valencianas y comprometiéndose a su devolución en un plazo máximo de 10 años y al abono de unos intereses anuales del $5 \%$.

\section{CUADRO II \\ EVOLUCIÓN DE LA ACTIVIDAD DEL POSFTO DEL COLEGIO DEL ARTE MAYOR DE LA SEDA (CANTIDADES EN LIBRAS VALENCIANAS Y EN LIBRAS DE 12 ONZAS EN EL CASO DE LA SEDA ADQUIRIDA)}

\begin{tabular}{|c|c|c|c|c|c|}
\hline Ejercicio & Fondo & $\begin{array}{c}\text { Seda } \\
\text { adquirida }\end{array}$ & Ingresos & Gastos & Beneficio \\
\hline $1760-61$ & 20022 & 7292 & 26898 & 25922 & 975 \\
\hline $1767-68$ & 3077 & 3278 & 15587 & 15357 & 230 \\
\hline $1768-70$ & 6526 & 5348 & 24685 & 24568 & 116 \\
\hline $1770-71$ & 8708 & 6824 & 30036 & 29916 & 1120 \\
\hline
\end{tabular}

Fuente: A.C.A.M.S.V. Sig. 3.6.4. Leg. 10.

En un principio, el pósito funcionó exclusivamente con este capital. Así, según las cuentas presentadas en el ejercicio 1760-61, el fondo inicial disponible el 16 de junio de 1760 era de 20.022 libras valencianas (ver cuadro n. $^{\circ}$ 2). Ahora bien, este dinero era manejado con la máxima intensidad, puesto que en dicho ejercicio se habian adquirido 7.292 libras valencianas (de 12 onzas) de seda hilandero e hilandera por un valor total de 20.714 libras, abonándose, además, los gastos de torcido y de otras contingencias hasta totalizar las 25.922 libras. Y el funcionamiento del pósito proporcionaba una buena rentabilidad, puesto que, tras satisfacer todos los gastos (incluyendo los intereses del préstamo obtenido), se logr6 en aquel ejercicio un beneficio de 975 libras, es decir, el $4.86 \%$ del fondo inicial disponible. La obtención de un pequeño beneficio anual permitió al colegio acumular el capital suficiente como para proceder a la devolución del préstamo en 1767 sin amenazar la continuidad del pósito. Ciertamente, su actividad se redujo notablemente en el ejercicio 1767-68, en el que el fondo disponible era solamente de 3.077 libras. De ahí que únicamente se adquiriesen 3.278 libras (de 12 onzas) de seda hilandera, hilandero y trama. Y el beneficio obtenido se elevó a 251 libras (230 si se atiende a la diferencia entre gastos e ingresos), lo que suponía el $8.15 \%$ del capital inicial disponible. Progresivamente, el fondo se fue incrementando, ya que en él se incluían, además, los ingresos extraordinarios que obtenía el colegio, como fue el caso de las 2.616 libras que en 1768 se percibieron de la ejecución de la sentencia del pleito sostenido con los exportadores sobre tanteo de la seda que se arrastraba desde 1762. Así, en el ejercicio 1770-71 el fondo ya ascendía a 8.708 libras, lo que permitió la adquisición y torcido de 6.824 libras (de 12 onzas) de seda, lográndose un beneficio del $12.86 \%{ }^{17}$. La existencia de este capital fue lo que permitió al colegio participar como socio en la Compañía de Nuestra Señora de los Desamparados.

17 Las cuentas derivadas de la administración del pósito pueden verse en A.C.A.M.S.V. Sig. 3.6.4. Leg. 10 .

Hispania, LVII/1, núm. 195 (1997) 93-114 
Como se ha señalado anteriormente, el logro de un abastecimiento regular de materias primas por parte de las fábricas era un objetivo compartido por la burguesía sedera, ya que podía resultar beneficioso para el desarrollo de sus propios negocios particulares. De ahí que la Junta de Comercio de Valencia se mostrase dispuesta a potenciar esta actividad patrocinando en 1765 la creación de una nueva compañía por acciones ${ }^{18}$. Su objetivo no se limitaba al ámbito sedero, sino que perseguía garantizar el correcto abastecimiento de materias primas para todas las fábricas existentes en la "Ciudad y Reyno" de Valencia. De ahí que la compaña se declarase abierta a toda la sociedad y que, a diferencia de los proyectos anteriores, los artesanos sederos no lograsen ninguna prerrogativa que les facilitase su control. El capital se reuniría por medio de la emisión de acciones de 200 libras, aunque para facilitar la participación de mayor número de personas se admitiría la suscripción de cuartas partes de una acción por valor de 50 libras. Los órganos de gobierno previstos para regir la sociedad eran bastante simples, otorgándose su control a los mayores accionistas, ya que se requería ser propietario de un mínimo de 5 acciones para poder acceder a alguno de los cargos. Estos estaban constituidos básicamente por 2 directores, 1 tesorero y 1 secretario, aunque se preveía también el nombramiento de 6 "conciliarios" para que asistiesen a las reuniones de la Junta Directiva en representación de los accionistas. Todos ellos debían de ser elegidos por la Junta General de Accionistas, en la que sería necesario poseer 2 acciones para disponer de un voto, aunque ningún socio podía acumular más de tres votos. Finalmente, en el último capítulo se preveía que si el fondo de la compañía lograse ser tan elevado que superase las necesidades del abastecimiento de las fábricas, se podrían emprender los negocios que se considerasen convenientes, pero cuidando siempre de evitar la competencia con la iniciativa privada. Así, aquellos se limitarian a los que "...los particulares comerciantes no pueden practicar por necesitarse de muy copioso caudal y haver éste de estar empleado largo tiempo...n. En este caso, se solicitaría protección real y la concesión de franquicias y privilegios.

Sin embargo, la política gubernamental caminaba en estos momentos por unos derroteros muy diferentes. Y de ahí que la Junta General de Comercio contemplase con'mucha reticencia este proyecto. En la orden que emitió el 11 de octubre de 1765 advertía que en los capítulos elaborados no se había adoptado expresamente «...regla ni providencia alguna que remueva los escrúpulos de los monopolios...». La orientación liberalizadora que estaba tomando la política económica entorpecía, por tanto, la aprobación del proyecto. Y, así, aquella orden era acompañada por la exigencia de la introducción de tantas modificaciones en los capítulos elaborados inicialmente que los vocales encargados del tema por la Junta de Comercio de Valencia llegaron a considerar que,

is A.M.V. Documentación Lonja. Caja 80. Expediente con fecha 14-10-1765. Aparte de los capitulos de la compañía y de los informes y consideraciones que se realizaron al respecto, en este expediente se encuentra también la orden de la Junta General de Comercio de 11 de octubre de 1765 que exigió la introducción de una serie de modificaciones que acabaron haciendo inviable el proyecto.

Hispanict, LVII/I, nùm. 195 (1997) 93-114 
con el pretexto de impedir los monopolios, se había llegado a dar a la compañ́a «...peor condición que la de cualquier particular comerciante...». De ahí que, aunque insistiesen en la utilidad de la compañía y en el posible papel que podía ejercer en la exploración de nuevos mercados, el proyecto acabase siendo abandonado. De nuevo, como en la década de 1740, la falta de apoyo gubernamental contribuía al fracaso de un proyecto que, en abstracto, parecía favorable para el desarrollo de las manufacturas valencianas.

\section{UNA GRAN OPORTUNIDAD PERDIDA: DESARROLLO Y CRISIS DE LA COMPAÑÍA DE NUESTRA SEÑORA DE LOS DESAMPARADOS}

La Compañía de Nuestra Señora de los Desamparados fue la única sociedad por acciones promovida por el artesanado sedero valenciano que logró superar ampliamente la fase del mero proyecto. Sin embargo, su actividad ha sido escasamente analizada por la historiografía. Las pocas referencias que dedica a ella la obra de V. Martínez Santos ${ }^{19}$ insisten en la modestia de la empresa y en su casi exclusiva dedicación a la comercialización de seda torcida, prestando poca atención al tejido, del que sólo se aportan algunos datos sobre las remesas realizadas a Cádiz entre 1779 y 1784 , época crítica para la sedería debido a las repercusiones de la guerra contra Inglaterra. Pero un análisis minucioso de su documentación nos ha permitido constatar que la compañía llegó a alcanzar una entidad muy importante. Tras su laboriosa creación, sus acciones acabaron gozando de una amplia aceptación en la sociedad valenciana, lo que permitió reunir un capital próximo a las 200.000 libras. $\mathrm{Y}$ de ahí que su intervención en el mundo productivo fuese bastante intensa, actuando como una especie de "Verleger" que, debido a sus características propias, podría haber jugado un papel crucial en el desarrollo de la sedería valenciana. Por tanto, resulta muy conveniente analizar las razones de su fracaso, que arrancan en gran medida de las propias condiciones de su surgimiento.

La creación de la Compañía de Nuestra Señora de los Desamparados fue una clara reacción defensiva del artesanado ante la agudización de sus dificultades como consecuencia de la mala cosecha de 1771. Como ya se ha indicado, su reducción al $42 \%$ de la obtenida el año anterior provocó una creciente paralización de las fábricas, como evidenciaron los 2.436 telares parados que se contabilizaron en el registro efectuado por el colegio en febrero de 1772. Las autoridades locales y el propio colegio trataron de aliviar la tensión social que provocaba esta situación recurriendo a los remedios tradicionales: la caridad y el trabajo en obras públicas. Pero algunos artesanos buscaron soluciones más imaginativas y revitalizaron la vieja aspiración para la constitución de una compañía por acciones. Parece que la idea la apuntó la «sociedad de oficiales» del colegio del arte mayor de la seda ya a principios de

\footnotetext{
19 Martinez Sants, V. Op. cit. Págs. 105-111.
} 
1772, proponiendo la intervención en el proyecto de los colegios de torcedores y tintoreros. Y si bien éstos la consideraron atractiva, el arte mayor de la seda no le prestó atención. Así lo interpretaron 20 maestros de este colegio, quienes en abril de 1772 interpusieron una demanda judicial en contra de la corporación ante el tribunal de intendencia ${ }^{20}$. En ella, aparte de insistir en la dramática situación que creaba la inactividad entre los maestros, se aludía a la crónica escasez estacional de materia prima que éstos sufrían, alegando que, aunque la próxima cosecha fuese abundante, «...solo servirá para abastecer algunos cortos meses, como es experiencia práctica en todos los años...». Pero, sobre todo, se cargaba el acento en los perniciosos efectos que se derivaban del control mercantil de la fábrica, ya que los comerciantes sólo encargaban la elaboración de ropas «...que por comisiones tienen ya vendida antes de estar trabajada..." y tenían tendencia a abandonar los negocios con demasiada facilidad, pues «...en faltándoles el provecho igual al primitivo, se retira con su dinero, dejando sin crédito la fábrica y sin tener consuelo al pobre maestro...». Por todo ello, se solicitaba que se apremiase al colegio a adherirse al proyecto de constitución de una compañía por acciones con intervención de los restantes colegios de torcedores y tintoreros.

Aunque el impulso del proyecto pudo partir de los sectores más modestos del artesanado, y el colegio del arte mayor de la seda lamentase que «...un pensamiento como el propuesto se aya emprendido por el modo judicial...", lo cierto es que dicha corporación gremial asumió su ejecución ya en julio de 1772, acordando incluso que los fondos del pósito de seda constituyesen el núcleo inicial de su capital. Y el 23 de septiembre de 1772 se aprobaron los capítulos iniciales que debían de regir su actividad ${ }^{21}$. En un principio, la compañía tenía un carácter exclusivamente artesanal, y de ahí que se la conociera como la compañía de los maestros del colegio del arte mayor de la seda de Valencia; puesto que sólo éstos podían participar en ella, estando vetado el acceso para los restantes sectores sociales. Así, por ejemplo, la posibilidad de transmisión de las acciones contenía esta importante limitación «...con tal que el nuevo dueño y poseedor sea legítimamente maestro, hijo o viuda de maestro del colegio y arte mayor de la seda de esta ciudad y Reyno, y no en otra persona...». Teniendo en cuenta el medio artesanal al que se dirigía, el valor de las acciones se fijó en una cantidad muy modesta: 20 libras. Pero aún así se consideró necesario otorgar a los maestros un plazo de un año para facilitarles la aportación de este capital. Y, considerando que sería muy difícil reu-

20 A.M.V. Tribunal de Comercio. Año 1772. Expediente n. ${ }^{\circ} 55$. Aparte de las referencias existentes en este expediente, en el libro de deliberaciones del colegio del arte mayor de la seda se alude el 3 de febrero de 1772 al memorial presentado por la «sociedad de oficiales». A.C.A.M.S.V. Sig. 2.5.2. Libro 5. Deliberación de 3-2-1772. Desconocemos cualquier referencia sobre las actividades de esta sociedad, aunque puede que tuviera su origen en la compantia por acciones que constituyeron los of iciales deì colegio en 1747. Ver su acta impresa en B.U.V. Sig. Var.F-6/3.

21 B.U.V. Sig. F-301. Folleto n. ${ }^{\circ} 5$. Aparte de los capítulos de la compañía, el folleto recoge también las órdenes de la Junta General de Comercio de 30 de julio y de 12 de diciembre de 1773 que aprobaron el proyecto con diversas modificaciones.

Hispania, LVI1/1, núm. 195 (I997) 93-114 
nir una cantidad elevada, se estipuló la posibilidad de admitir «dinero a premio" de otras personas. En todo caso, se estipuló claramente que ningún socio podía sacar su dinero hasta que hubiesen transcurrido 12 años desde la adquisición de las acciones, y este plazo jugó un papel clave en la disolución de la sociedad, como veremos posteriormente. Por su parte, los órganos directivos tenían una estructura bastante compleja. La Junta de Dirección estaba constituida por un director general, dos subdirectores, el mayoral del colegio del arte mayor de la seda, un secretario, un contador y un tesorero. La Junta de Consejo ampliaba la de dirección con la inclusión de otros seis vocales escogidos entre los que hubiesen ejercido cargos directivos y los mayores accionistas, debiéndose reunir, al menos, una vez al año para aprobar el balance de la sociedad. Y la Junta General de Accionistas se reuniría cada cuatro años, disponiéndose de un voto por cada cinco acciones, aunque limitándose a cinco el número máximo de votos de que podía disponer cada accionista. En todo caso, la vinculación al colegio del arte mayor de la seda era tan intensa que se estipulaba que todas las juntas se reunirían en sus locales, en donde también se encontraría la tesorería y el depósito general de la compañía.

Sin embargo, el carácter de la compañía se transformó radicalmente debido a las modificaciones que impuso la Junta General de Comercio para su aprobación. El fracaso en el que normalmente desembocaban los grandes proyectos artesanales, como estaba ocurriendo por estas fechas con la Compañía de la Real Fábrica de Paños Superfinos de Segovia ${ }^{22}$, determinó que esta institución acogiese la iniciativa con mucho recelo. Pero la propia Junta de Comercio de Valencia tampoco la contemplaba con mucha simpatía, y fueron sus objeciones las que finalmente asumió aquella en la orden de 30 de julio de 1773. La principal preocupación era la competencia que la compañía ejercería a la iniciativa privada en la elaboración y comercialización de los tejidos. Así, el informe emitido por la Junta de Comercio de Valencia consideraba muy útil que la sociedad se orientase a favorecer el abastecimiento de materias primas para las fábricas, pero alegaba que su intervención en el resto del negocio sedero "...embebe en si el perjuicio de los particulares que fabrican y comercian en tegidos, y esto no será aumentar ni mantener los telares, sino trasladar el comercio y fábrica de tegidos de manos de los particulares a las de la compañía.... ${ }^{23}$. De ahí que propusiese la limitación de esta actividad, lo que aceptó de forma radical la Junta General de Comercio prohibiéndola completamente y aceptando sólo que la sociedad pudiese prestar dinero a los fabricantes tomando como garantía los tejidos que hubiesen elaborado. Sin

22 Garcia SANZ, A. Desarrollo y crisis del Antiguo Régimen en Castilla la Vieja. Economía y sociedad en tierras de Segovia (1500-1814). Madrid, 1977. Pags. 229-231.

23 A.M.V. Documentación Lonja. Caja 107. Resulta interesante constatar que también en los casos de las Companías de Granada y Toledo se ha apreciado una similar oposición inicial al proyecto por parte de los empresarios y comerciantes sederos alegando la competencia que podían ejercer a la iniciativa privada. Ver Rodriguez González, M. C. Op. cit. Pág. 49; Rico Linage, R. Op. cit. Pág. 160; y García Rujpérez, M. Op. cil. Pág. 50-51 y 59-60

Hispania, LVtU/t, núm. 195 (1997) 93-114 
embargo, la compañía recurrió esta grave limitación de su actividad. Y en la orden de 12 de diciembre de 1773, en la que se aprobaban definitivamente sus capítulos, la Junta General de Comercio acabó aceptando que se pudiesen elaborar tejidos con las sedas que sobrasen en cada ejercicio anual a...para que de este modo no quede la compañía expuesta a graves pérdidas si en un año escaso en que huviese hecho sus acopios a precios subidos no tuviese salida, y luego llegase un año abundante que hiciese bajar los precios, fuera de que el reducir las sedas a tegidos siempre da fomento a nuestro comercio activo...». De esta forma, a pesar de la oposición inicial de la burguesía sedera, se abría la puerta a las actividades empresariales de la compañía.

Mayor trascendencia tuvieron para su futuro las otras modificaciones propuestas por la Junta de Comercio de Valencia y aceptadas íntegramente por la General, ya que transformaron la propia naturaleza de la compañía. Consistieron básicamente en la eliminación del carácter exclusivamente artesanal que tenía el proyecto original, abriendo la posibilidad de participar en su accionariado al conjunto de la sociedad. Ahora bien, esta ampliación de las bases sociales de la compañía se consideró compatible con la reserva de los cargos directivos para los maestros del arte mayor de la seda. $Y$ éste parece el origen de los problemas que acabarían conduciendo a la disolución de la compañía, puesto que en la Junta General de Accionistas los artesanos carecían de prerrogativas que les garantizasen el control de la sociedad, dependiendo directamente los votos del número de acciones poseídas. El precio de éstas, que se consideraba demasiado bajo, fue elevado a 50 libras, aunque admitiéndose la posesión de medias acciones de 25 libras. Y, consiguientemente, se redujo a cuatro la cantidad de acciones requeridas para poseer un voto, manteniéndose en cinco el número máximo de votos que podía poseer cada accionista. Realmente, la contradicción existente entre una Junta General de Accionistas en la que los votos dependían del capital poseído y unos cargos directivos que debían de proceder del colegio del arte mayor de la seda fue el principal problema de la compañía, ya que su crecimiento acabó convirtiendo a los maestros en los accionistas minoritarios.

En efecto, la compañía comenzó su existencia real en octubre de 1773, tres meses después de la primera orden de la Junta General de Comercio en la que se aprobaban sus capítulos con las modificaciones aludidas. El capital inicial procedió del propio colegio del arte mayor de la seda, que invirtió en acciones 7.700 libras de las 11.929 que constituían el fondo del pósito ${ }^{24}$. Posteriormente, el propio colegio fue ampliando su capital hasta alcanzar las 9.825 libras que acumulaba en acciones a partir de diciembre de 1778. Aparte del colegio, los primeros accionistas fueron prácticamente todos maestros del arte mayor de la seda, y sólo a partir de la aprobación definitiva de los capí-

${ }^{24}$ La deliberación del colegio en la que se decidió transferir a la compañía los fondos del pósito de sedas tuvo lugar el 13 de septiembre de 1773 , y en ella se acordó invertir en acciones 7.700 libras, depositar en la misma compañia en concepto de administración 3.600 libras, y destinar las restantes 629 libras que quedaban del fondo del pósito a satisfacer los posibles gastos que surgiesen. A.C.A.M.S.V. Sig, 2.5.2. Libro 5. Deliberación de 13-9-1773.

Hispania, LVI1/1, núm. 195 (1997) 93-114 
tulos de la compañía por la Junta General de Comercio en diciembre de 1773 comenzaron a interesarse en ella personas procedentes de otros medios sociales ${ }^{25}$. De todas formas, como puede apreciarse en el cuadro n. ${ }^{\circ} 3$, el ritmo de suscripción de acciones fue bastante lento en un principio, hasta el punto de que en octubre de 1775 (dos años después de su inicio) la compañía sólo disponfa de un capital de 37.150 libras. Fueron seguramente los excelentes resultados que se obtuvieron en estos primeros ejercicios los que determinaron la notable aceleración del ritmo de suscripción de acciones que se experimentó en los años siguientes, llegando a su máxima intensidad en el ejercicio 1776 77, en el que prácticamente se dobló el capital de la compañ́a. Sólo a partir de 1779 se produjo un claro reflujo en la aportación de nuevo capital, debido, en gran medida, a las dificultades que atravesaba la sedería como consecuencia de la guerra contra Inglaterra. Pero ya entonces la compañía había alcanzado una gran dimensión, logrando que se hubiesen suscrito acciones por un valor total de algo más de 190.000 libras. Se trataba de una cifra que cuadruplicaba, como mínimo, el capital que tenían invertido directamente en el negocio sedero los comerciantes-fabricantes cuyo inventario se ha logrado localizar ${ }^{26}$.

\title{
CUADRO III
}

RITMO DE SUSCRIPCIÓN DE ACCIONES DE LA COMPANIA DE NUESTRA SENORA DE LOS DESAMPARADOS (CAPITAL EN LIBRAS VALENCIANAS Y EJERCICIOS COMPRENDIDOS ENTRE EL 1 DE NOVIEMBRE Y EL 31 DE OCTUBRE)

$\begin{array}{ccc}\frac{\text { Ejercicio }}{1773-74} & \text { Capital suscrito } & \text { Total acumulado } \\ 1774-75 & 20.050 & 20.050 \\ 1775-76 & 17.100 & 37.150 \\ 1776-77 & 31.350 & 68.500 \\ 1777-78 & 65.350 & 133.850 \\ 1778-79 & 38.275 & 172.125 \\ 1779-80 & 12.375 & 184.500 \\ 1780-81 & 7.500 & 192.000 \\ 1781-82 & 925 & 192.925 \\ & 400 & 193.325\end{array}$

Fuente: A.C.A.M.S.V. Sig. 2.3.1. Libro 2.

\begin{abstract}
25 A.C.A.M.S.V Sig. 2.3.1. Libro 2. Este es el libro de accionistas de la compañia, y de él procede toda nuestra información sobre el proceso de suscripción de acciones. Cabe advertir que los resultados, que se han plasmado en los cuadros n." 3 y 4 , proceden del análisis de los titulares iniciales de las acciones, sin tener en cuenta las modificaciones que pudieran producir las transacciones ulteriores. De todas formas, éstas fueron muy escasas, concentrándose entre 1778 y 1780 y consistiendo básicamente en la amortización del capital por parte de la compañía al recurrir al derecho de tanteo. De ahí que en 1782, por ejemplo, el capital social se hubiese reducido a 159.600 libras (Ver A.C.A.M.S.V. Sig. 3.4.5. Leg. 4. Exp. n. ${ }^{\circ} 9$ ). Sin embargo, a partir de 1780 , las pérdidas derivadas de la crisis comercial que se estaba sufiiendo y la escasez de dinero en efectivo paralizaron las transacciones.

${ }_{26}$ FRANCH, R. El capital comercial valenciano en el siglo XVII. Valencia, 1989.
\end{abstract}


Sin embargo, el crecimiento de la compañía provocó una sustancial modificación de su base social, puesto que la mayor parte del capital procedió de sectores ajenos al mundo artesanal. En efecto, el capital total de 193.325 libras que se llegó a suscribir fue proporcionado por 334 accionistas distintos. Pues bien, los maestros del arte mayor de la seda sólo constituyeron el $27.24 \%$ de éstos, y el capital de 17.125 libras que aportaron representaba únicamente el $8.86 \%$ del total. Su situación de reducida minoría sólo era levemente atenuada agregándoles las 9.825 libras invertidas por el colegio del arte mayor de la seda. Pero, aún así, el capital en manos de los artesanos sederos sólo representaba el $13.94 \%$ del total. Además, su carácter minoritario se veía acentuado por el hecho de que solían formar parte del sector más modesto del accionariado. En el cuadro n. ${ }^{\circ} 4$ se puede apreciar que los accionistas que disponían sólo de media o de una acción representaban el $26.64 \%$ del total, mientras que entre los maestros este sector se elevaba al $47.25 \%$. Y, lo que es más grave, los que tenían menos de cuatro acciones, y, consiguientemente, no tenían derecho a voto en la Junta General de Accionistas, eran el $41.61 \%$, porcentaje que entre los maestros se elevaba al $62.63 \%$. De hecho, los artesanos sederos eran sólo 34 (35 si se les suma el colegio) de los 195 accionistas con derecho a voto, por lo que ni siquiera numéricamente tenían una fuerza significativa. Por tanto, atendiendo a la base social de la que procedía el capital, la Compañía de Nuestra Señora de los Desamparados se había alejado mucho de sus raíces artesanales. Sin embargo, sus estatutos no se habían adaptado a las nuevas circunstancias, y reservaban el control de los cargos directivos al sector impulsor que era ya claramente minoritario. La escasa representatividad de este grupo tenía que provocar necesariamente la aparición de graves enfrentamientos, y más teniendo en cuenta que sus intereses y objetivos podían ser muy distintos de los de la mayoría de los accionistas.

\section{CUADRO IV}

COMPARACIÓN ENTRE LA DISTRIBUCIÓN DEL CAPITAL SUSCRITO POR LOS ARTESANOS SEDEROS Y LA DEL CONJUNTO DE LOS ACCIONISTAS DE LA COMPANIA DE NUESTRA SEÑORA DE LOS DESAMPARADOS (CAPITAL EXPRESADO EN LIBRAS VALENCIANAS)

\begin{tabular}{rcccc} 
Intervalos capital & \multicolumn{2}{c}{ Artesanos sederos } & \multicolumn{2}{c}{ Total accionistas } \\
$0-50$ & $\underline{\mathrm{N} .}$ & $\underline{\%}$ & $\underline{\mathrm{N}}$. & $\frac{\%}{26.64}$ \\
$51-199$ & 43 & 47.25 & 89 & 14.97 \\
$200-1.000$ & 14 & 15.38 & 50 & 46.70 \\
$1.001-5.000$ & 33 & 36.26 & 156 & 9.88 \\
$5.001-15.000$ & 1 & 1.10 & 33 & 1.80
\end{tabular}

Fuente: A.C.A.M.S.V. Sig. 2.3.1. Libro 2.

Parece que fue la crisis experimentada por la sedería a raiz del estallido de la guerra contra Inglaterra en 1779 lo que provocó las mayores discordias. Como correspondía a una compañía que había surgido con el objetivo 
de favorecer la actividad de las fábricas, la sociedad no paralizó inmediatamente su actividad, que era la reacción más lógica aplicando unos criterios estrictamente empresariales. $\mathrm{Y}$ así, los tejidos fabricados con fondos propios en el año 1780 se situaron en unos niveles similares a los de los ejercicios anteriores. Pero, como, además, el colegio del arte mayor de la seda le cedí las 10.000 libras que le había otorgado el arzobispo Francisco Fabián y Fuero para combatir la desocupación de los artesanos, el resultado fue que en dicho año se alcanzó la cifra más elevada de producción de tejidos de seda de toda la historia de la compañía. Y como este récord tuvo lugar en un contexto de retracción de la demanda como consecuencia del bloqueo aplicado por Inglaterra, los stocks de sedas torcidas y manufacturadas se amontonaron y provocaron graves pérdidas en los ejercicios 1779 80 y $1780-81$.

Precisamente en noviembre de 1781 la compañía cumplía su segundo cuatrienio de actividad, por lo que se debía de convocar a la Junta General de Accionistas. Y fue en ella en donde afloraron las mayores discordias entre la mayoría de los accionistas y el sector artesanal dirigente. La Junta fue convocada para el día 2 de enero de 1782, y parece que en ella se planteó la necesidad de modificar los capítulos que regían la actividad de la compañía con el fin de acabar con el exclusivismo artesanal en la ocupación de los cargos directivos. Así se deduce de la actitud defensiva que adoptó el colegio del arte mayor de la seda, ya que sometio el acuerdo allí adoptado al dictamen de sus abogados, los cuales aconsejaron que «...sin perder tiempo se represente a la superioridad para que nunca se perjudiquen los derechos del colegio, ni se alteren los citados capítulos de la compañía.... ${ }^{27}$. Lo cierto es que en aquella reunión se procedió al nombramiento de una Junta de Apoderados para encargarse del gobierno de la sociedad que vulneraba claramente lo previsto en sus estatutos. Puesto que, de sus ocho miembros, sólo dos (el director y el propio mayoral del colegio del arte mayor de la seda) eran artesanos sederos. Progresivamente, la Junta fue marcando distancias con respecto a la corporación artesanal que había promovido el surgimiento de la compañía. A partir de mediados de marzo de $\mathbf{1 7 8 2}$ dejó incluso de reunirse en la propia sede del colegio, haciéndolo en casa de uno de sus miembros, Don Gaspar Ferrer y Pinós, caballero de la orden de San Juan de Jerusalén. Y, cuando en octubre del mismo año el sector artesanal de la Junta trató de modificar el rumbo exigiendo que las reuniones se realizasen de nuevo en la sede del colegio, se planteb un agudo conflicto que hubo de resolver el propio intendente. Este apoyó al sector mayoritario de la Junta, exigiendo al director de la compañía y al mayoral del colegio que acudiesen a las reuniones convocadas en casa de Don Gaspar Ferrer bajo pena de 100 libras en caso de oponerse a ellas. Con el apoyo del colegio, ambos aceptaron esta decisión a regañadientes, puesto que se resignaron a acudir a las reuniones por el "apremion del intendente pero «...protestando qualquier asunto que ocurra en orden a la innovación de capí-

27 A.C.A.M.S.V. Sig. 2.5.2. Libro 5. Ver deliberación de 5-3-1782.

Hispania, LVII/1, núm. 195 (1997) 93-114 
tulos...* 28. Es evidente que a partir de entonces se incrementaron los recelos del artesanado sedero hacia el sector dirigente de la compañía, por lo que el colegio dejó de considerar a ésta como una entidad propia que merecía la pena mantener.

El progresivo distanciamiento del colegio del arte mayor de la seda con respecto a la compañía se puso claramente de manifiesto en noviembre de 1784, cuando el mayoral propuso a la corporación aprovechar que el año siguiente se cumplía el tercer cuatrienio de la creación de la compañía para solicitar el reintegro del capital que el colegio había invertido en ella, conforme lo autorizaba el capítulo $8^{\circ}$ de su acta de fundacion. Tras el dictamen favorable de los abogados del colegio, en febrero de 1785 se acordó proceder formalmente a ello. Pero, a pesar de esta decisión, el colegio continuaba teniendo una actitud muy celosa en defensa de sus prerrogativas. Y así, en la misma deliberación se trató la dimisión que había presentado el director de la compañía y se acordó que si la Junta de Apoderados nombraba para sustituirle a una persona que no fuese maestro del arte mayor de la seda, se recurriese la decisión ${ }^{29}$. La solicitud del colegio para que se le reintegrasen sus fondos fue acogida con mucha acritud por la Junta de Apoderados de la compañía, que calificó como «extravagante pensamiento" el hecho de que «...el principal author interesado y que se constituyó como garante de la compañía, que es el colegio, se separe de ella...». Y más teniendo en cuenta que, según la junta, las graves pérdidas que se habian experimentado procedían de *...la falta del debido manejo y dirección en los años en que estuvieron todos los empleos de la compañ́a en individuos del mismo colegio..... Por tanto, frente a aquella petición, la junta proponía que se convocase una Junta General de Accionistas para que deliberase sobre la continuidad o disolución de la sociedad. Esta tuvo lugar el 3 de noviembre de 1785, y en ella se impuso la propuesta de disolución por 113 votos frente a 4130 . De esta forma, fracasaba estrepitosamente el último y más importante proyecto impulsado por el artesanado sedero para favorecer el desarrollo de la manufactura y preservar su independencia económica.

\section{v) CONCLUSIONES.}

El artesanado sedero valenciano experimentó una notable transformación de su condición económica tradicional durante el siglo xviII. A los factores estructurales que ya dificultaban su actividad (elevado precio de la

28 Los conflictos planteados en las reuniones de la Junta de Apoderados en octubre de 1782 pueden verse en A.C.A.M.S.V. Sig. 3.4.5. Leg. I. En el libro de deliberaciones del colegio se da noticia de la decisión final del intendente y del acuerdo tomado por la corporación y el director de la compañia. A.C.A.M.S.V. Sig. 2.5.2. Libro 5. Deliberación de 12-11-1782.

29 A.C.A.M.S.V. Sig. 2.5.2. Libro 5. Ver deliberaciones de 26-1 1-1784 y 11-2-1785.

30 A.C.A.M.S.V. Sig. 3.4.5. Leg. 5. Exps. n. ${ }^{\circ}$ 13-15.

Hispania. LVI1/1, núm. 195 (1997) 93-114 
materia prima, estacionalidad en su comercialización, oscilaciones de la cosecha, etc.) se añadió el atractivo que para las clases comerciales adquirió el negocio sedero en dicha centuria, al amparo de la expansión experimentada por la manufactura. Junto con la propia diferenciación interna que se estaba produciendo en el mundo artesanal, la intervención del capital comercial propició un intenso desarrollo del "Verlagssystem", amenazando gravemente la independencia económica de que había gozado el artesanado tradicional. El cambio fue tan sustancial que los propios artesanos adquirieron conciencia de la necesidad de contrarrestar la evolución, empren. diendo numerosas inciciativas con esta finalidad. Resulta significativo que los primeros proyectos fuesen promovidos por los miembros de las categorías artesanales más modestas, materializándose en la constitución de grandes compañías por acciones que asumiesen un papel empresarial menos lesivo para sus intereses que el que estaba desarrollando la iniciativa privada. Sin embargo, la misma espontaneidad de estas iniciativas acabó determinando su fracaso final. Mejores resultados se lograron cuando el estímulo procedió de la propia corporación artesanal. Sin embargo, sus objetivos eran menos ambiciosos, ya que la diferenciación social existente entre los miembros del colegio del arte mayor de la seda determinaba que sus intereses comunes se redujesen a facetas muy primarias de la actividad manufacturera. De ahí que el colegio se limitara a promover la constitución de un pósito que facilitara el abastecimiento de materias primas por parte de las fábricas, renunciando a intervenir en actividades empresariales que podían competir con los posibles negocios particulares efectuados por sus miembros. La burguesía sedera compartía los mismos criterios, como revela la tentativa de la Junta de Comercio de Valencia, controlada entonces por ella, para constituir en 1765 una gran compañía por acciones orientada a garantizar el abastecimiento de materias primas por parte de las fábricas. Lógicamente, se oponía, en cambio, a la constitución de compañías de carácter artesanal que asumiesen funciones empresariales. En esta línea se situaron sus cruciales objeciones a los estatutos de la Compañía de Nuestra Señora de los Desamparados. Aunque sus esfuerzos para evitar la intervención de esta sociedad en el negocio de elaboración y comercialización de tejidos de seda acabaron fracasando, el resto de sus propuestas, asumidas por la Junta General de Comercio, transformaron radicalmente la naturaleza de la compañía, eliminando su carácter artesanal y permitiendo la participación en su accionariado del conjunto de la sociedad valenciana. Esta circunstancia favoreció el rápido crecimiento de la compañía. Sin embargo, su consolidación se vio amenazada por la grave contradicción derivada del hecho de que los artesanos, que se habian convertido en el sector minoritario del accionariado, continuaran desempeñando en exclusiva los cargos directivos, según preveían los estatutos originales. Los intentos de adecuación de éstos a las nuevas bases sociales que se produjeron durante la crisis comercial de 1779-82 suscitaron una firme oposición por parte del colegio del arte mayor de la seda. Y cuando éste perdió el control de la compañía, optó por desmarcarse de ella y forzar su disolución. No cabe duda de que los artesanos

Hispania, LVIU/, แúm. 195 (1997) 93-114 
desaprovechaban así una gran oportunidad para contribuir activamente al desarrollo de la sedería. En todo caso, el fracaso de su principal iniciativa sancionaba su incapacidad para frenar o modificar en su favor las nuevas relaciones de producción que se estaban imponiendo en el ámbito manufacturero. 